\title{
RECURSOS HÍDRICOS E DESENVOLVIMENTO SUSTENTÁVEL (Escala de Necessidades Humanas e Manejo Ambiental Integrado)*
}

\author{
OSIRES CARVAlho ${ }^{1}$ \\ Mestrado em Geografia Universidade Estadual do Ceará e \\ FLÁVIO RODRIGUES ${ }^{2}$
}

\section{Iniciando a discussão}

A conservação da natureza, proteção ambiental, ordenamento do espaço regional, ação política, monitoramento e gestão ambiental são áreas estratégicas para o alcance do Desenvolvimento Sustentável. Pela reconhecida vulnerabilidade geoambiental de alguns dos seus domínios paisagísticos, além da defesa contra as consequiências da seca, recuperação e ampliação da biodiversidade, conservação dos solos, exploração dos recursos naturais e educação ambiental, todos os pontos onde ocorre o cerne da sustentabilidade para o desenvolvimento eqüitativo dos recursos hídricos, fato resultante de sua imanência enquanto recurso e de sua transcendência como sói acontecer às essencialidades da vida.

\footnotetext{
* Este artigo foi produzido a partir da Dissertação de Mestrado defendida na UECE pelo segundo autor, sob a orientação do primeiro, conforme listada nas referências bibliográficas.

${ }^{\prime} \mathrm{PhD}$. em Recursos Naturais -Imperial College de Londres. Prof. do Mestrado em Geografia da UECE.

${ }^{2}$ Doutorando do Programa de Pós-graduação em Geografia da UFF. Mestre em Geografia (Análise Geoambiental e Ordenação do Território nas Regiões Semi-Áridas e Litorâneas - MAG/UECE) e licenciado e bacharel em Geografia pela UFC.
} 
A partir desta compreensão intergrada, uma abordagem sobre bacias de drenagem se insere nos princípios do Desenvolvimento Sustentável, extrapolando-se a idéia técnica e polarizada do termo. Tais unidades devem ser analisadas dentro de uma perspectiva múltipla e diversificada, destacando-se sua essencialidade como assim dependência das necessidades humanas frente aos seus diversos usos. Observe-se que, deste fato, quase sempre resultam variados matizes de degradação ambiental.

Sob este prisma, mostra-se necessário estudar os recursos hídricos como fator básico de melhoria da qualidade ambiental. Concebendo-se as bacias e sub-bacias hidrográficas como unidades de manejo geoambiental, para fins de gestão e conservação, transforma a administração do espaço em tarefa mais lógica e com maior grau de eficiência para o gestor designado para a tarefa.

\section{Água - o recurso fundamental}

Os filósofos gregos há milênios, afirmavam que tudo provém da água. Conhecer as propriedades dessa substância, para eles significava debruçar-se sobre muitas propriedades da própria vida, pois o estudo das águas muito nos diz sobre a essência da natureza e do Universo. A propósito, a tese de que tudo se originou da água já fora defendido por Tales de Mileto, há 2.500 anos.

Sem dúvida, a água é um recurso essencial, seja como solvente universal, componente bioquímico dos seres vivos, como meio de sobrevivência para várias espécies vegetais e animais, como elemento de valores sociais, culturais e estéticos, seja enquanto insumo na produção de bens e serviços de consumo intermediários e finais. Tudo depende da água na sua mais ampla acepção - do silicon chip no seu notebook à verdura hidropônica parte de sua salada natural. Ainda, dentre suas propriedades físico-químicas, destaca-se sua grande estabilidade térmica. Traduzida como capacidade de acumular calor e de resistir a variações térmicas acentuadas, a água propicia a estabilidade físico-química interna dos organismos, conferindo-lhes higidez biológica e funcional.

Pode-se afirmar que a água é um recurso natural renovável, porém exaurível. É impactada por ações socioeconômicas que lhe confere degradabilidade, reduzindolhe a quantidade utilizável em intervalos espaço-temporal freqüentemente mais curtos. Genericamente, as características da água, em termos de ações básicas, são:

\footnotetext{
$\checkmark$ "a água é um recurso natural de múltipla finalidade;

$\checkmark$ a água é essencial à vida e insubstituível na grande maioria dos usos;

$\checkmark$ a água é parte da paisagem e insumo produtivo, industrial, agroindustrial, agrícola, pecuário e numa série de outras atividades;

$\checkmark$ a água é irregularmente distribuída no espaço e no tempo;
} 
$\checkmark$ a água é degradável, renovável e reciclável, seja naturalmente pelo ciclo hidrológico ou artificialmente (THEODORO et al., 2002:18)."

Conforme Branco (1993) e Rebouças et al., (1999), mais de 1,3 bilhão de km de água cobrem $3 / 4$ da superfície terrestre e integram a atmosfera. Este valor, transformado em toneladas, perfaz um montante superior a 1.360 quatrilhões de toneladas de águas geograficamente distribuídas dessa forma:

Tabela 1 - Distribuição das águas no Globo terrestre

\begin{tabular}{lcc}
\hline Distribuição & Porcentagem & Trilhões de toneladas \\
\hline Água salgada & 97,5 & 1.326 \\
(Óceanos e mares) & 2,5 & 127.959 \\
Água doce & Valores derivados de água doce: & \\
& 68,9 & 88,1 \\
Calotas polares e geleiras & 29,9 & 38,2 \\
Água subterrânea & 0,3 & 0,38 \\
Rios e lagos & 0,9 & \\
Outros reservatórios & & \\
\hline
\end{tabular}

Fonte: Elaborado a partir de Branco (1993) e Rebouças et al., (1999)

Naturalmente, o ciclo hidrológico consegue renovar a capacidade de resiliência das águas, diferenciando-as de outros recursos naturais, por ocorrer em diferentes estados e formas. Apesar da quantidade de água na Terra, ao longo dos ciclos geológicos, ainda ser teoricamente a mesma, há indícios de que a partir dos dois últimos séculos, principalmente, sua disposição espacial em relação à quantidade, qualidade e potabilidade, no que tange as águas doces, vem se observando modificações no plano da oferta, traduzido pela presença cada vez mais freqüente da escassez, de pronto atribuída ao acentuado crescimento demográfico global.

A capacidade de suporte dos corpos hídricos, na realidade, vem sendo ultrapassada, com a diminuição do poder de depuração de resíduos e compostos - cada vez mais complexos e não-biodegradáveis. Embora alguns rios ainda mantenham uma autodepuração razoável, conforme o fluxo de matéria, energia e informação como no caso do Rio Pacoti na RMF - aquele caso é genérico em comparação com os rios da metrópole em consideração, como de outras regiões metropolitanas no País. Particularmente, essa é a resultante mais evidente da não universalização do saneamento básico e do baixo nível de Educação Formal e Ambiental da população que habita no entorno das capitais e grandes aglomerados urbanos que vicejam ao longo do espaço geográfico do Estado. 
A escassez de água frente aos seus usos múltiplos, que também incluem atividades produtivas, gera uma redução na sua disponibilidade e qualidade, materializada tanto na crise atual da saúde quanto na esperada crise de médio prazo no provimento da alimentação básica, agravando ainda mais os índices de qualidade de vida e outros indicadores sociais de bem-estar, para a população hoje e as futuras gerações, no contexto regional.

Com esta realidade, considerando as bacias e sub-bacias hidrográficas como unidade territorial de planejamento, torna-se urgente reler os paradigmas de desenvolvimento regionais que, atrelados ao nacional e ao internacional, frente à globalização, determinam padrões de manejo das atividades campesinas. Ademais, as culturas locais são mais facilmente adaptadas à realidade nacional do que às tecnologias de ponta na ambientação de novas culturas, isto pressupondo estratégias ecologicamente harmônicas.

Como estratégia inicial, a partir dos usos múltiplos dos recursos hídricos, será dada prioridade à satisfação das necessidades humanas básicas e de proteção da capacidade de suporte dos ecossistemas - preferencialmente dos hidrossistemas. Posteriormente, tais recursos assumiriam características básicas enquanto indutor pecuniário ao desenvolvimento econômico, via cobrança tarifária pelo uso da água, com isso evitando uma situação de dumping ambiental ou de subsídio econômico explícito.

A gestão ambiental dos recursos hídricos, discutindo um modelo de desenvolvimento sustentado para as bacias de drenagem, materializa-se como inerente ao seu processo de desenvolvimento econômico, social e de harmonia ambiental. Inicialmente, esta discussão perpassa o entendimento de bacia hidrográfica $(\mathrm{BH})$ como âncora de desenvolvimento territorial, por se constituir uma unidade da realidade socioambiental para os trabalhos mais densos no campo da geografia, com enfoque inter, multi, pluri e transdisciplinares, voltados ao gerenciamento dos recursos hídricos.

\section{Bacia Hidrográfica como unidade ambiental de planejamento}

Os recursos hídricos devem ser avaliados em um contexto sócio-espacial amplo, transcendendo uma visão exclusivamente limnológica. As bases científicas para o conhecimento de um sistema aquático para a realização de prognósticos da qualidade hídrica e sua recuperação e manejo só serão possíveis através de um instrumento que viabilize estudos integrados dos aspectos socioambientais, os quais emanam da concretude e das possibilidades analíticas do conceito de (BH), aqui ratificado por Paula et al., (1997: 257), como sendo:

"sistemas terrestres e aquáticos geograficamente definidos, compostos por sistemas fisicos, econômicos e sociais, onde se conjugam questões ambientais". 
A representação espacial de uma (BH) resguarda as paisagens e, no seu âmago, ocorrem importantes interações ambientais, socioeconômicas e antropogênicas podendo a mesma ser eleita como unidade de planejamento territorial mais adequada, extrapolando a mera gestão dos recursos hídricos. Esta perspectiva contempla um manejo ambiental integrado e sustentável, mesmo porque a gestão dos recursos hídricos se insere no processo eficiente de manejo e gestão ambiental.

Assim, uma bacia hidrográfica denota características geoambientais, formando uma unidade natural indissociável e interatuante. É um sistema complexo - dado o número de elementos e variáveis -, em que as relações mútuas entre os seus componentes estruturais possibilitam a análise integrada do meio ambiente, permitindo uma acurada avaliação dos aspectos, quer físicos, quer econômicos e sociais.

Uma bacia engloba relações de causa-efeito e de políticas externas (como a de preços, por exemplo) - por isso deve ser considerada como sistema "multicomposto", que inclui desde a água aos elementos do potencial geoecológico, sobrepostos, dialeticamente, por aspectos sócio-políticos e econômicos.

Devido à essencialidade que a água encerra, a $(\mathrm{BH})$ frequientemente é utilizada como referencial geográfico para o planejamento, manejo e aproveitamento de recursos naturais. Assim, esta entidade ecológica tem se tornado uma unidade básica ao gerenciamento ambiental, isto é, um recurso natural como âncora dos "processos regionais de desenvolvimento". Além das instituições que trabalham com recursos hídricos, a comunidade, a propriedade privada ou os municípios por ela banhados, são todos responsáveis pela sua sustentabilidade (ROSS e PRETTE, 1998:102), preferencialmente ecossocial.

Ao gerenciar a água, há a obrigação indireta de gerenciar diversos processos ambientais e planejar o espaço territorial, respeitando os parâmetros de sustentabilidade ambiental dos sistemas naturais remanescentes.

Mesmo que uma bacia ou sub-bacia seja considerada uma unidade de planejamento, ela jamais poderá encerrar o planejamento e a gestão dos recursos hídricos qual uma panacéia para os problemas ambientais vigentes, ao tempo em que a atividade econômica, sem parametrização definida, freqüentemente não respeita os limites dos divisores de água.

Todavia, é inquestionável que qualquer uso dispersivo da água afeta o equilíbrio hidrológico da própria bacia. Amiúde, a vocação econômica, os aspectos geoecológicos e o uso cultural de cada bacia tornam-nas singulares. Por estes fatores, a bacia hidrográfica é a unidade natural mais adequada para a gestão dos recursos hídricos. No entanto, a administração de uma bacia não é uma tarefa fácil. Apenas um pequeno detalhe neste domínio: além de unidades naturais, as mesmas ainda sofrem injunções enquanto unidades político-administrativas.

No caso, há bacias em que suas áreas são de superposição jurídica de diferentes níveis e esferas políticas, compreendendo os governos municipais e o próprio governo estadual - sem esquecer de produtores rurais, empresários e da sociedade 
civil. Consequientemente, os conflitos relativos à ocupação e uso dos recursos naturais é uma realidade, inquestionável.

A partir desta trama, pode-se dizer que as múltiplas interações do uso da água em uma bacia hidrográfica dão-se no nível proporcional à demanda de água para seus diversos usos. Por isso, é crucial para este trabalho, que a presente bacia seja tida como uma unidade ambiental de análise e parte de uma realidade interdisciplinar de análise, no campo da gestão integrada de bacias hidrográficas.

\section{Gerenciamento de bacias hidrográficas}

Gestão ambiental é a etapa de materialização das idéias, desenvolvimento dos projetos com propostas práticas, para que sejam minoradas as condições vigentes de insustentabilidade.

Neste bojo, entende-se por manejo de bacia hidrográfica o conjunto de ações e atividades necessárias à conservação e/ou preservação das águas superficiais e subsuperficiais - incluindo-se atividades afins, como forma de proteção do potencial biótico e abiótico, recreação, educação, balneabilidade, pesquisa e usos múltiplos da água, assim como as atividades de administração e gerenciamento.

Como exemplo de gestão de $(\mathrm{BH})$, tem-se a formação de consórcios intermunicipais. Este modelo já é praticado no gerenciamento de recursos hídricos nos EUA, Japão e Europa, desde 1930. No Brasil, somente na segunda metade dos anos de 1980 é que iniciativas desta ordem surgiram através do pioneiro Consórcio Intermunicipal das Bacias do Piracicaba e Capivari (Benevides \& Coimbra, 1992).

Daquele período até o presente momento, os recursos hídricos no Brasil deixaram de ser geridos somente pelo Estado, para serem ordenados pelo Sistema Nacional de Gerenciamento de Recursos Hídricos - SINGREH (Lei 9.433, de 08/01/1997) - fato ocorrido em meio ao processo de desregulamentação do Estado. O SINGREH é formado pelos mais diversos representantes, incluindo usuários e entidades correlatas atuantes na sociedade civil.

Destaquem-se os comitês de bacias, que assumem e decidem sobre as conseqüências positivas e negativas resultantes da gestão do processo, ao passo que agregam custos inevitáveis ao acesso à água. Isto tem uma enorme capacidade educativa, porque a população aos poucos entende suas relações e limitações em relação ao meio ambiente que integra.

No Estado, o "Programa Águas do Ceará" destacou um elenco de projetos e programas voltados à política de águas. O Projeto de Desenvolvimento Urbano e Gestão dos Recursos Hídricos do Estado do Ceará-PROURB-CE, implantou múltiplas ações dos poderes público estadual e municipal no desenvolvimento de áreas estratégicas de infra-estrutura urbana e suporte hídrico para o desenvolvimento estadual, com destaque à regularização do abastecimento de água para seus usos múltiplos, através do aumento da oferta e do gerenciamento (Rodrigues, 1999). 
Quadro 1 - Organismos e instâncias componentes do SINGREH

\begin{tabular}{|c|c|c|}
\hline Organismos e instâncias & Funções & Objetivo \\
\hline $\begin{array}{l}\text { Conselho Nacional de } \\
\text { Recursos Hídricos. }\end{array}$ & $\begin{array}{l}\text { Deliberativa e normativa } \\
\text { máxima do Sistema. }\end{array}$ & $\begin{array}{l}\text { Definir as diretrizes da Política } \\
\text { Nacional de Recursos Hídricos. }\end{array}$ \\
\hline $\begin{array}{l}\text { Agência Nacional } \\
\text { de Águas - ANA. }\end{array}$ & $\begin{array}{l}\text { Autarquia de regime } \\
\text { especial, vinculada ao } \\
\text { Ministério do } \\
\text { Meio Ambiente. }\end{array}$ & $\begin{array}{l}\text { Implementar, em sua esfera de } \\
\text { atribuições, a Política Nacional } \\
\text { de Recursos Hídricos e coordenar o } \\
\text { Sistema Nacional de } \\
\text { Gerenciamento de Recursos } \\
\text { Hídricos. }\end{array}$ \\
\hline
\end{tabular}

\begin{tabular}{lll}
\hline $\begin{array}{l}\text { Conselhos estaduais de recursos } \\
\text { hídricos dos estados e }\end{array}$ & $\begin{array}{l}\text { Responsável pela resolução Aprovar planos estaduais e distritais } \\
\text { Distrito Federal. }\end{array}$ & $\begin{array}{l}\text { das questões e conflitos } \\
\text { nas bacias hidrográficas } \\
\text { em que atuam. }\end{array}$ \\
\hline Comitês de bacias hidrográficas. & $\begin{array}{c}\text { Delibera e normatiza no } \\
\text { âmbito de uma bacia }\end{array}$ & $\begin{array}{c}\text { Aprovar os planos de bacia, os } \\
\text { valores da cobrança e as prioridades }\end{array}$ \\
& ou sub-bacia hidrográfica. de uso dos recursos hídricos em sua \\
Conta com a participação & área de atuação. \\
de usuários, do poder & \\
público nos três niveis & \\
& e da sociedade civil \\
& organizada. \\
\hline
\end{tabular}

Agências de água.

Secretaria executiva,
mediante autorização
do outorgante, da
cobrança pelo uso dos
recursos hídricos
na bacia.

Executar as decisões dos comitês de bacias
Participar de todas as instâncias decisórias do SINGREH.
Articular entre si, e com todos os outros participantes do sistema, planos e projetos.

Fonte: Elaborado a partir de MMA (2002)

Sob esta égide, a Bacia do Pacoti foi priorizada para a otimização de seu aproveitamento hidráulico para a $\mathrm{RMF}$, preferencialmente para o abastecimento público de água no Sistema Pacoti-Riachão-Gavião, na interligação das Bacias Metropolitanas.

Ademais, outros programas estão em fase de implementação junto ao Governo Federal e instituições financeiras internacionais para otimizar o manejo das $(\mathrm{BH})$ do território cearense, respectivamente: PROÁGUA - Programa de Desenvolvimento Sustentável do Semi-Árido Brasileiro, e PROGERIRH - Programa de Gerenciamento e Integração dos Recursos Hídricos, PROASIS - Programa de Águas 
Subterrâneas, PRODHAM - Programa de Desenvolvimento Hidrogeoambiental das Bacias.

Outros aspectos pormenorizados a respeito da gestão dos recursos hídricos do Ceará são encontrados em diversos estudos, dentre os quais destacam-se: Ceará 1992, 1994a, 1999; Rodrigues, 1999, Campos et al., 2001. Em linhas gerais, cabe referenciar a definição e caracterização das principais funções, com as respectivas sub-funções em termos de gestão, oferta e preservação das águas nesse Estado.

Quadro 2 - Funções do sistema de gestão de água e demais sistemas, consideradas no Plano de Recursos Hídricos do Ceará de 1992

\begin{tabular}{|c|c|c|}
\hline & Gestão & $\begin{array}{l}\text { Planejamento } \\
\text { Administração } \\
\text { Regulamentação }\end{array}$ \\
\hline & Oferta & $\begin{array}{l}\text { Nucleação artificial } \\
\text { Represamento } \\
\text { Poços } \\
\text { Cisternas }\end{array}$ \\
\hline \multirow{3}{*}{$\begin{array}{l}\mathrm{U} \\
\mathrm{s} \\
\mathrm{o}\end{array}$} & Consuntivo & $\begin{array}{l}\text { Abastecimento, irrigação, abastecimento industrial, } \\
\text { aqüicultura, abastecimento urbano. }\end{array}$ \\
\hline & Não Consuntivo & $\begin{array}{l}\text { Geração hidrelétrica, navegação fluvial, lazer, pesca e } \\
\text { piscicultura extensiva, assimilação de esgotos }\end{array}$ \\
\hline & $\begin{array}{l}\text { Preservação } \\
\text { Complementares }\end{array}$ & $\begin{array}{l}\text { Ciência e tecnologia, meio ambiente, planejamento } \\
\text { global, incentivos econômicos, defesa civil }\end{array}$ \\
\hline
\end{tabular}

Fonte: Campos et al., (2001).

Particularmente no Pacoti - considerando a água como um bem econômico e, portanto, com um preço exagerado pelo seu uso e - observando a bacia hidrográfica como unidade para o exercício de ações e a participação dos usuários nos Comitês de Bacias, que terão poderes consultivos e deliberativos, temos esses fatores que contribuem para o entendimento de uma bacia como uma Unidade de Planejamento Regional (Figura 1). Para tanto, faz-se necessária à elaboração de um modelo de desenvolvimento emancipatório, o qual extrapole a discussão técnica e polarizada do termo desenvolvimento sustentável, discutindo ampla e coletivamente a categoria sustentabilidade de processos ecossistêmicos. 


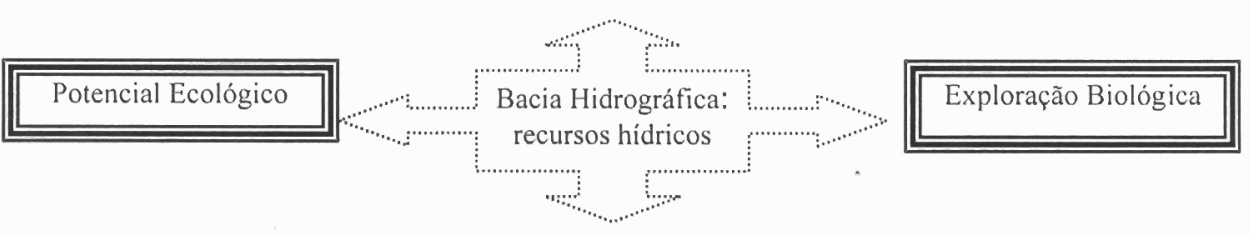

Políticas Econômicas e Atividades sociais - uso e ocupação do solo (estrutura fundiária, urbanização etc), demografia, industrialização, impactos ambientais, projetos sociais, educação ambiental, macro-projetos...

Fig. 1. Aspectos relevantes à gestão da Bacia Hidrográfica do Pacoti

\section{Desenvolvimento Sustentável e gestão dos recursos naturais}

\section{Necessidades humanas e recursos naturais}

$\mathrm{O}$ atendimento das necessidades humanas engendradas pela globalização demanda incessantemente bens e serviços, exigindo grandes quantidades de matéria e energia.

Para Cavalcanti et al., (1997), a inter-relação entre necessidades, provedores e bens é contínua e dinâmica, configurando-se em estilos de desenvolvimento de culturas, onde as necessidades humanas classificam-se em: categorias existenciais (ser, ter, fazer e estar) e categorias axiológicas (necessidade de subsistência, proteção, afeto, participação, entendimento, criação, ócio, identidade e liberdade).

Neste caso, os provedores são tudo aquilo que possa representar formas de ser, ter, fazer e estar, colaborando para satisfação das necessidades humanas. É o desenvolvimento sustentado, acreditam aqueles autores - mostrando a base conceitual do desenvolvimento humano integral. A idéia primordial deste modelo é a de exibir as categoriais existências e axiológicas das necessidades humanas.

Desta forma, Alier (1996) citado por Leite (2001) observou que:

Para atender às crescentes necessidades individuais e coletivas engendradas pelo processo de globalização, há um consumo endossomático de energia - alimentação, que depende da biologia humana-, e há um uso exossomático de energia- gastos energéticos com vestuário, moradia transporte, produção. Esses gastos energéticos estão relacionados com o modelo de desenvolvimento, tanto que as diferenças do uso exossomático de energia entre países pobres e ricos continua muito grande. 
Sem esquecer que as necessidades humanas requerem progressivamente a substituição de bens e serviços por suprimentos da mesma ordem, exigindo grandes quantidades de água, mas com nova tecnologia e demanda crescente por energia, aumentado o consumo de Produção Primária Líquida (PPL) - recurso alimentar básico a todos os seres que não realizam fotossíntese (MERICO, 1996).

Realmente, a apreensão do ambiente, comumente, é exterior à existência humana, pois este tem sido apreendido somente como um recurso natural a ser explorado. Sinais de degradação que ameaçam a segurança ambiental, como a escassez da água doce, indicam a necessidade de se mudar o padrão de vida de agrupamentos sociais, que beira a exaustão. Deveras, a exclusão social e degradação ambiental são como o desenvolvimento e a conservação: as duas faces de uma mesma moeda (Ribeiro, 2001).

Estes fatos são sinais de que estamos passando por uma crise ambiental - a qual questiona o paradigma vigente, por seus impactos destrutivos sobre os recursos naturais e pela degradação da população mundial, marginalizada frente aos benefícios urbano-industriais.

Novo paradigma: Desenvolvimento Sustentável (DS)

Carvalho (2001:25), em artigo publicado sobre globalização, desenvolvimento sustentável e meio ambiente, afirmou que:

$O$ crescente aumento nos niveis de informação e conhecimento tecnológico vem gerando um maior sentido de consciência e participação sobre a importância dos recursos naturais e do meio ambiente como fatores de produção, geração de amenidades e equilíbrio ecológico. Assim, o planejamento da utilização dos recursos naturais, em harmonia com o meio ambiente, mostra-se como condição básica para que se alcance a sustentabilidade do desenvolvimento econômico, em nível regional, nacional, continental e mundial. É o paradigma da Globalização, com harmonia ecológica, em que se vive no mundo hoje.

O DS surge, nas últimas décadas, como um novo paradigma possível de ordenar a dinâmica econômica, a salvaguarda ambiental e promover a equiidade intertemporal das gerações humanas. Neste prisma, os recursos hídricos são estratégicos, dada sua essencialidade à vida e como insumo produtivo.

A rigor, a definição oficial diz que o DS é o "desenvolvimento que satisfaz as necessidades do presente sem comprometer as habilidades das futuras gerações de satisfazerem suas necessidades" (Relatório Brundtland, 1987 in Alcântara, 2000:9).

Entretanto, a expressão DS é complexa e repleta de ideologias, exigindo uma discussão pormenorizada de suas implicações e desdobramentos. 
Dentre os conceitos e objetivos que dão conteúdo ao termo Desenvolvimento Sustentável - mostrando a diversidade de opiniões contraditórias -, destacam-se as conceituações feitas por cientistas, técnicos e políticos, de um lado, incluindo à discussão política e ética e o discurso dos organismos e entidades internacionais de outro, ressaltando, principalmente, o gerenciamento dos recursos naturais.

Alguns autores, de modo sutil, apregoam o que deveria ser Desenvolvimento Sustentável - ou, em outro diapasão, o que gostariam que ele fosse em termos de realidade factual. Outros procuram equalizar Desenvolvimento Sustentável com sustentabilidade ecológica. Alguns afirmam ser preciso pôr limites ao crescimento econômico porque ele é insustentável do ponto de vista da disponibilidade global de recursos. Por último, mas sem exaurir a bateria de conceitos dissonantes, existem os que incluem o adjetivo sustentável na idéia tradicional de desenvolvimento, como se tudo pudesse ser resolvido no domínio semântico.

Desta forma, a idéia de (DS) é usada por interesses diversos, como símbolo de um consenso, ideal inatingível no contexto de um sistema globalmente desigual e desconforme. Tal idéia transparece no plano discursivo, apresentando ambigüidades gritantes, mas sem explicitar a realidade atual dos conflitos sociais e econômicos resultante do uso dos recursos naturais. As diferentes esferas da sociedade, os diversos profissionais e os diferentes níveis de governo possuem idéias e aspirações naturalmente diferentes, o que requer maior sintonia na sua utilização do conceito de Desenvolvimento Sustentável.

Há confusão entre o que seja o termo Desenvolvimento Sustentável, Sustentabilidade Ecológica e Sustentabilidade, que não podem ser usados como sinônimos, pois: DS está ligado à melhoria na qualidade de vida humana dentro dos limites da capacidade-suporte dos ecossistemas; sustentabilidade ecológica, por sua vez, aplica-se somente a recursos renováveis - diz-se da natureza homeostática dos ecossistemas naturais, à sua autoperpetuação; e sustentabilidade, como é destacada, é ambígua: nada do que é físico cresce indefinidamente.

Embora seja amplo o conjunto de definições do termo, todos são unânimes em destacar sustentabilidade como palavra-chave. Porém, a discussão sobre (DS) induz a uma reflexão sobre os paradigmas vigentes que põem em risco a economia ambiental, a inclusão social e a dinâmica econômica, pensando não só no hoje, mas no amanhã e nas gerações que inexoravelmente virão.

Para não instrumentalizar o termo Desenvolvimento Sustentável de uma única perspectiva, a discussão coletiva e dialógica sobre o conceito de sustentabilidade deve ser socialmente posta em pauta. Até mesmo para evitar a construção de jargões ou clichês e, principalmente, para se decidir o que deve ser sustentado! Por quê, para quem e por quanto tempo? O presente estratagema tem como base a orientação de Baroni (1992).

No Brasil, a prática de um desenvolvimento alternativo que extrapole o simples aumento do consumo e da produção de bens materiais e serviços, é um desafió político, institucional e intelectual, praticamente intransponível. Através de um 
processo que permita aos indivíduos, comunidades e governos o resgate de seus direitos e a autonomia de decidir seu próprio futuro - respeitando os diversos estilos de vida, culturas, valores tradicionais e as necessidades sociais -, esse desejo afigura-se como "um sonho de uma noite de verão", muito embora a realidade exija a realização de algo mais nessa direção.

É importante ressaltar que, além das idéias macroeconômicas, deve ser considerado, no processo de desenvolvimento, o lócus - ou seja, a área de participação comunitária das populações e grupos sociais.

Desta forma o desenvolvimento local no caso do Pacoti reativaria a economia, dinamizaria a sociedade local, conforme o aproveitamento ótimo dos recursos endógenos, possibilitando o estímulo e diversificação do crescimento econômico, melhorando o bem-estar da comunidade local, enquanto compromisso que aceita o espaço como o lugar de solidariedade ativa, mudando o comportamento e atitude dos grupos e indivíduos.

Assim, a apropriação política do termo Desenvolvimento Sustentável deve ser assumida pela sociedade em geral, para que sua omissão não se coadune com um simples eufemismo revestido de um ecologismo piegas e pelego. O nível de miséria econômica e cultural existente no País é o veículo ideal para a propagação desse EVANGELISMO ECOLÓGICO! Principalmente como forma de manter o status quo vigente nas últimas décadas.

\section{Observações finais}

As transformações sócio-ambientais verificadas nas últimas duas décadas, apontam para uma crescente pressão social sobre a dotação de recursos naturais. Os recursos hídricos, por exemplo, tiveram sua demanda elevada em face da diversificação dos seus usos múltiplos e do crescimento demográfico - geralmente resultando em impactos ambientais que determinam em pioria nos índices de desenvolvimento social.

Ações localizadas e desarticuladas entre municípios banhados por bacias ou sub-bacias, malgrado, ou mesmo por decisões exclusivas em nível de Estado, não promovem uma mudança estrutural na gestão dos recursos naturais - notadamente os recursos hídricos. Somente em se articulando todos os segmentos da sociedade, convocando a contribuição dos atores políticos, econômicos, sociais, ambientais e, sem dúvida, os usuários diretos do pacote de recursos naturais - beneficiários primordiais da sustentabilidade que se pretende implantar nas bacias de drenagem, com base numa adequada política de gestão ambiental.

Mesmo bem elaborados, os planos de Desenvolvimento Sustentável para as bacias hidrográficas - não se pode esquecer -, com sua eficiência mínima em termos de resultados previstos, somente serão materializados se houver simultaneidade de ação nas diferentes escalas administrativas - nacional, regional e local -, de 
forma a que não se inibam possíveis alternativas de sustentabilidade emergentes do âmbito municipal.

A utilização dos recursos naturais e a harmonia com o meio ambiente, de forma sustentável, deverão ter como viga central de sustentação o planejamento ambiental e o desenvolvimento de mecanismos eficientes na gestão dos recursos hídricos. Assim, estarão em pauta a manutenção do desenvolvimento econômico, de forma equiitativa, do nível local ao global, uma vez que o paradigma da globalização deve internalizar o meio ambiente nas questões produtivas. Quiçá, em dias vindouros, a relação sociedade versus natureza, aliada a essencialidade do recurso, destaque a água e sua vitalidade com tonalidades ainda de maior realce.

\section{RECURSOS HÍDRICOS E DESENVOLVIMENTO SUSTENTÁVEL (ESCALA DE NECESSIDADES HUMANAS E MANEJO AMBIENTAL INTEGRADO)}

Resumo: O presente artigo aborda a questão dos recursos hídricos e a sustentabilidade do desenvolvimento para discussão de subsídios para melhoria do uso da água, - elemento essencial à vida. -, no âmbito de bacias e sub-bacias hidrográficas. Qualquer ação ou política desenvolvida para tratar dos recursos hídricos, só colherão bons resultados se considerarem as bacias de drenagem como unidades de planejamento e gestão ambiental. A título de exemplo, considerou-se o Plano de Recursos Hídricos do Estado do Ceará, concebendo-o como um estudo de caso da Sub-bacia Metropolitana do Pacoti - Ceará.

Palavras-chave: recursos hídricos, desenvolvimento sustentável, bacia hidrográfica, gestão e qualidade ambiental.

\section{HYDROLOGICAL RESOURCES AND SUSTAINABLE DEVELOPMENT (HUMAN NECESSITIES SCALE AND INTEGRATED ENVIRONMENTAL MANAGEMENT)}

Abstract: The present work approaches the hydrological resources within the sustainable development realm, taking into account the uneven resource distribution in Semi-Arid regions such as the Northeastern Brazil and the Pacoti river basin in the State of Ceará. Although obvious, the water resources are essential to life. Based on this principle the idea of sustainable development is fully discussed on a local and global basis, so that to emphasize how low are the human and social development indexes related to local inhabitants. A poor State in a poor Region of a developing country, such as Brazil, shouldn't operate without local political bias. Despite the local improvement translated into a more active participation of locals, some rural projects are producing better results to the rural people. Planning the years ahead seems to be the only way to provide a better life to future generation.

Keywords: water resources management; sustainable development; social planning and development; river basin

\section{BIBLIOGRAFIA}

ALCÂNTARA, Lúcio. 2000. Desenvolvimento Sustentável. Brasília: Senado Federal,Coleção idéias, Brasília. 
BARONI, Margaret. 1992. Ambigüidades e deficiências do conceito de desenvolvimento sustentável. In Revista de Administração - /USP. 32(2): 14/24. São Paulo.

BENEVIDES, Vinícius. F. de S. \& COIMBRA, Roberto, M. 1992. Gerenciamento de Recursos hídricos. In Semana de debates sobre Recursos Hídricos e meio Ambiente, Piracicaba: Consórcio Intermunicipal das Bacias do Rios Piracicaba e Capivari, DAEE, FUNDAP. São Paulo.

BRANCO, Samuel. M. 1993.Água: origem, uso e preservação. Moderna. São Paulo.

CAMPOS, Nilson et al. 2001. Gestão de Águas: princípios e práticas. ABRH. Porto Alegre-RS.

CAVALCANTI, Agostinho P. B. et al. 1997. Desenvolvimento sustentável e planejamento: bases teóricas e conceituais. UFC - Imprensa Universitária. Fortaleza-CE.

CARVALHO, Osires 2001. Globalização, Desenvolvimento Sustentável e Meio Ambiente. In Revista de Saneamento Ambiental. Resíduos industriais: a incineração ganha mercado. Ano XII - n ${ }^{\circ} 18$. São Paulo.

CEARÁ. 1992. Secretaria de Recursos Hídricos. Plano de Recursos Hídricos do Estado do Ceará, Fortaleza: SRH. Fortaleza-CE.

.1994a. Secretaria. de Planejamento e Coordenação. Projeto Áridas. Grupo de Trabalho II.2. Sustentabilidade do Desenvolvimento do Semi-Árido sob o ponto de vista dos Recursos Hídricos. SEPLAN. Fortaleza-CE

1999. Companhia de Gestão dos Recursos hídricos - COGERH. Plano de Gerenciamento das águas das Bacias Metropolitanas. COGERH, FortalezaCE.

LEITE, Ana. M. F. 2001. Estudo da sustentabilidade de sócio-ecossistemas urbanos através da "Pegada Ecológica": Região Metropolitana de Fortaleza. UFC, 99p. (Dissertação de Mestrado). Fortaleza-CE.

MERICO, Luiz F. K.1996. Introdução à economia ecológica. (Cap. 1). Ed. da FURB. Blumenau - SC.

MINISTÉRIO DO MEIO AMBIENTE/MMA. 2002. Código das águas. [On line]. [cited 01.01.2002. http://www.mma.gov.br.

PAULA, João A. de et al. 1997. Biodiversidade, população e economia: uma região de Mata Atlântica. Belo horizonte: UFMG/Cedeplar; ECMXC; PADCT/CIAMB. Belo Horizonte-MG.

REBOUÇAS, Aldo. da C. 1997. Água na região Nordeste: desperdício e escassez. In Revista Estudos Avançados 11(29): Edusp. São Paulo.

1999. Águas doces no Brasil: capital ecológico, uso e conservação. Escrituras Editora. São Paulo.

RIBEIRO, Wagner, C. 2001. A ordem ambiental internacional. Contexto. São Paulo. 
RODRIGUES, Hugo. 1999. A gestão da água: discurso e prática no contexto cearense. In Amora, Z. B et al. O Ceará: enfoques geográficos. FUNECE. Fortaleza-CE.

RODRIGUES, Flávio. 2003. Recursos Naturais e Desenvolvimento Sustentável: Subsídios ao Manejo Geoambiental na Sub-bacia do Baixo Pacoti - CE. UECE, 154p. (Dissertação de Mestrado). Fortaleza-CE.

RODRIGUES, Hugo \& CARVALHO, Osires. Turismo e a economia do meio ambiente. In: Jornal O POVO (Caderno de Economia - Análises econômicas), p. 28. Fortaleza - CE.

ROSS, Jurandyr L. S. \& PRETTE, Marcos E. D. 1998. Recursos hídricos e bacias hidrográficas: âncoras do planejamento e gestão ambiental. In Revista. do Dept $^{\circ}$ de Geografia da FFLCH - USP. N ${ }^{\circ}$ 12. P. 89-121. São Paulo.

THEODORO, Suzi H. et al. 2002. Conflitos e uso sustentável dos recursos naturais. Garamond. Rio de Janeiro. 